\title{
Ciclos de Negócios e Políticas Econômicas: uma Análise da Indústria do Rio Grande do Sul
}

\section{Business Cycles and Economic Policies: An Analysis of the Industry of Rio Grande do Sul}

\author{
Lívia Carolina Machado Melo \\ Fábio Augusto Reis Gomes ${ }^{a}$
}

\begin{abstract}
Resumo: Este trabalho tem como objetivo estimar os ciclos econômicos da indústria do Rio Grande do Sul e analisar como políticas econômicas afetam tais ciclos. Para tanto, os ciclos da produção industrial mensal, de janeiro de 2002 a dezembro de 2016, são estimados por meio de modelos autorregressivos com mudança de regime de Markov. A especificação selecionada possui quatro defasagens e dois regimes - expansão e recessão - e indica que o Rio Grande do Sul apresenta períodos mais longos de recessão do que de expansão. Estimadas as probabilidades de a indústria estar em recessão em cada mês da amostra, confrontam-se tais informações com variáveis que representam as políticas monetária e fiscal, além da evolução do câmbio. Há evidência de que o aumento do gasto do governo federal está correlacionado com a melhora do desempenho da indústria gaúcha.
\end{abstract}

Palavras-chave: Ciclos econômicos. Modelo de mudança de regime markoviano. Políticas econômicas. Rio Grande do Sul.

Abstract: This study aims to estimate the economic cycles of Rio Grande do Sul industry to analyze how economic policies affect such cycles. For this purpose, the cycles of monthly industrial production, from January 2002 to December 2016, are estimated by means of autoregressive models with Markov regime switching. The selected specification has four lags and two regimes - expansion and recession - and indicates that Rio Grande do Sul has longer periods of recession than expansion. Estimated the probabilities of the industry being in recession in each month of the sample, this information was confronted with variables that represent monetary and fiscal policies, besides the exchange rate evolution. There is evidence that increases in the expenditures of the state government are correlated with the improved performance of the industry from Rio Grande do Sul state.

Keywords: Economic cycles. Markov-Switching model. Economic policies. Rio Grande do Sul.

JEL Classification: E32; C24; E61

a Universidade de São Paulo (USP), Faculdade de Economia, Administração e Contabilidade de Ribeirão Preto (FEA-RP), Departamento de Economia. Ribeirão Preto, São Paulo, Brasil. 


\section{Introdução}

É de interesse da sociedade saber qual é o estado da economia, recessão ou expansão. No entanto, esse estado não é observável, sendo necessário estimá-lo. Para tanto, podem ser consideradas duas abordagens distintas: ciclos de negócios ou ciclos de crescimento. De acordo com Christoffersen (2000), a abordagem de ciclos de negócios identifica pontos de inflexão, picos e depressões, que, por sua vez, datam os períodos de expansão e de recessão, enquanto a abordagem dos ciclos de crescimento baseia-se em procedimentos de extração (estimação) de uma tendência para, então, identificar o componente cíclico residual da produção. Nesse caso, a expansão ocorre quando o nível de atividade está acima da tendência estimada e a recessão ocorre no caso oposto.

O objetivo deste trabalho é datar os ciclos de negócios da indústria do Rio Grande do Sul e relacioná-los a políticas econômicas, sendo utilizada a abordagem de ciclos de negócios, uma vez que a pergunta de pesquisa não demanda a estimação de uma tendência. De fato, essa abordagem tem sido utilizada recorrentemente para se estudar as flutuações econômicas no Brasil e em seus estados (CÉSPEDES; CHAUVET; LIMA, 2006; MEDEIROS; SOBRAL, 2007; MORAIS; PORTUGAL, 2003, 2007; MORAIS, 2013). De todo modo, é importante destacar que o presente trabalho se difere da literatura nacional por dois motivos: ao considerar um período mais longo, estende-se a datação dos ciclos da indústria gaúcha. Mais importante, são estimados modelos econométricos para se estudar a relação entre importantes variáveis macroeconômicas - juros, gasto do governo e câmbio - e os ciclos econômicos. Assim, este estudo contribui para o entendimento dos impactos de políticas econômicas sobre o nível de atividade, subsidiando o seu aprimoramento.

Dentre os métodos utilizados para a construção cronológica dos ciclos de negócios destaca-se o algoritmo desenvolvido por Bry e Boschan (1971), que identifica os pontos de inflexão entre períodos de expansão e de contração da série temporal usada para medir o nível da atividade econômica. Tal algoritmo impõe, a priori, que as fases do ciclo de negócios tenham um comprimento mínimo. O método desenvolvido por Hamilton (1989) relaxa tal hipótese ao assumir que a transição entre os regimes da economia é estocástica, sendo descrita por uma cadeia de Markov. Mais especificamente, Hamilton (1989) propõe um modelo autorregressivo para a taxa de crescimento do produto, cuja média depende do regime da economia. No regime de expansão, a taxa de crescimento média do produto é positiva, mas na recessão é negativa. O processo de estimação do modelo recupera, além dos parâmetros, a probabilidade de, em um dado período, a economia estar em recessão, o que possibilita a datação dos ciclos econômicos. 
Adota-se a abordagem de Hamilton (1989) para se realizar a datação dos ciclos de negócios da indústria gaúcha. ${ }^{1}$ De posse da probabilidade de recessão para cada período da amostra, emprega-se um modelo econométrico para investigar a relação entre os ciclos de negócios e variáveis macroeconômicas, no qual a variável dependente é o logaritmo da chance de ocorrer recessão e as variáveis dependentes são as proxies para a política monetária e fiscal, como defasagens da taxa de juros real e dos gastos do governo. ${ }^{2}$ Além dessas variáveis explicativas, consideram-se também as defasagens da taxa de câmbio nominal. ${ }^{3}$ A estimação é feita por meio do estimador de mínimos quadrados ordinários (MQO) aliado ao estimador robusto de Newey-West para a matriz de variância e covariância dos coeficientes estimados. Considera-se, também, uma correção para os erros padrões baseada no procedimento de bootstrap.

Ao aplicar o modelo autorregressivo com mudança de regime markoviano aos dados da indústria gaúcha de janeiro de 2002 a dezembro de 2016, obtiveram-se os seguintes resultados: tanto as expansões quanto as recessões são persistentes, mas a duração das expansões é inferior à duração das recessões, em média. Ao analisar a relação entre os ciclos de negócios e as variáveis macroeconômicas, concluiu-se que há considerável inércia na chance de ocorrer recessão, pois a sua primeira defasagem sempre se mostrou relevante, ao nível de significância de 1\%. Ademais, tem-se evidência de que aumentos na dívida do governo federal impulsionam a indústria gaúcha.

Além desta introdução, o trabalho está dividido em mais cinco seções: a segunda apresenta uma breve revisão da literatura sobre datação de ciclos; a terceira discute tanto as políticas econômicas adotadas no Brasil entre 2002 e 2016 quanto as características econômicas do Rio Grande do Sul; a quarta apresenta a base de dados e detalha a metodologia econométrica; a quinta apresenta os resultados; e, por fim, a sexta traz as considerações finais.

1 Segundo Billio, Caporin e Cazzavillan (2007), no caso norte-americano o algoritmo de Bry e Boschan (1971) e os modelos a la Hamilton (1989) têm demonstrado uma replicação razoavelmente precisa da cronologia de recessões do National Bureau of Economic Research (NBER) quando aplicada a dados agregados. No entanto, para os dados estaduais, a abordagem de Hamilton tem a vantagem de não exigir que as recessões sejam declínios absolutos da atividade econômica.

2 A chance de ocorrer recessão é dada por $\operatorname{Pr}[\mathrm{R} t]$ / (1-Pr [Rt]), em que Pr[Rt] é a probabilidade de ocorrer recessão no período t.

3 Evita-se o termo política cambial, pois no período analisado o câmbio é flexível. Embora o Banco Central tenha feito intervenções, essas foram pontuais, e não resultado de uma política sistemática de controle do câmbio. 


\section{Datação dos Ciclos Econômicos}

Nesta seção apresentam-se os modelos autorregressivos com mudança de regime usados para datar os ciclos de negócios da indústria gaúcha, bem como uma breve descrição de trabalhos da literatura nacional que se apoiam em tal metodologia.

\subsection{Modelos Autorregressivos com Mudança de Regime Markoviano}

O modelo autorregressivo com mudança de regime de Markov (MS-AR) proposto por Hamilton (1989) consiste em um modelo não linear, no qual a transição entre os regimes da variável dependente é estocástica. Assim, esses regimes são tratados como não observáveis e a transição entre eles é descrita por uma cadeia de Markov. De acordo com Krolzig (2003), por trás dessa abordagem está a hipótese de que certos parâmetros do modelo usado para descrever o nível de atividade econômica dependem de uma variável não observável que indexa os $n$ regimes (estados) da economia, diga-se $s_{t}=\{1, \ldots, n\}$ O número de regimes, $n$, é tal que compreenda ao menos um estado de expansão e outro de contração da economia, não sendo inferior a dois.

Ao modelar o produto nacional bruto (PNB) real da economia norte-americana, Hamilton (1989) considera dois regimes: recessão e expansão. Com isso, a transição entre esses regimes é dada pela seguinte cadeia de Markov ergódica:

$$
P=\left[\begin{array}{ll}
p_{11} & p_{12} \\
p_{21} & p_{22}
\end{array}\right]
$$

em que $p_{i j}$ é a probabilidade de ocorrer o estado $j$ no período $t$, dado que a economia estava no estado $i$ no período $t$ - 1 . Essas probabilidades de transição são constantes e, naturalmente, $p_{12}=1-p_{11}$ e $p_{21}=1-p_{22}$. Nota-se que essas probabilidades afetam o estado da economia, o que, por sua vez, define a datação dos ciclos de negócios. Finalmente, Hamilton (1989) estima a seguinte especificação:

$$
\Delta y_{t}-\mu\left(s_{t}\right)=\alpha_{1}\left(\Delta y_{t-1}-\mu\left(s_{t-1}\right)\right)+\cdots+\alpha_{4}\left(\Delta y_{t-4}-\mu\left(s_{t-4}\right)\right)+u_{t}
$$

em que $y_{t}$ é o logaritmo da variável usada para medir o nível de atividade, sendo $\Delta y_{t}$ a sua taxa de crescimento; $\alpha_{1}, \ldots, \alpha_{4}$ são parâmetros autoregressivos; $\mu\left(s_{t}\right)$ são taxas de crescimento média de cada regime; $u_{t} \sim i i d N\left(0, \sigma^{2}\right)$. Assim, essa especificação corresponde a um modelo autorregressivo de ordem quatro, com parâmetros autorregressivos constantes, mas com taxas de crescimento médias dependentes do estado da economia. Nota-se, ainda, que a variância do termo de erro também é constante, sendo um modelo homocedástico. A escolha de um modelo autorregressivo de ordem quatro está relacionada ao fato de Hamilton 
(1989) estudar dados trimestrais. Como mencionado, o autor considerou dois regimes, obtendo $\hat{\mu}_{1}<0$ e $\hat{\mu}_{2}>0$. Assim, $\mu_{1}$ e $\mu_{2}$ representam, respectivamente, a taxa de crescimento médio dos períodos de recessão e de expansão.

As probabilidades de transição, apresentadas na matriz 1, são estimadas juntamente com os parâmetros do modelo 2. Assim, após a estimação, é possível obter estimativas da duração de cada fase do ciclo de negócios. No caso de dois regimes, $p_{11}$ e $p_{22}$ são as probabilidades de a economia permanecer no mesmo regime entre dois períodos consecutivos e, assim, a duração dos regimes 1 e 2 são obtidas, respectivamente, por $1 /\left(1-p_{11}\right)$ e $1 /\left(1-p_{22}\right)$. Hamilton (1989) obteve $\hat{p}_{11}=0,7550$ e $\hat{p}_{22}=0,9049$, sendo a duração média das recessões 4,1 trimestres e das expansões, 10,5 trimestres. À época, a datação do NBER implicava que a duração da recessão era de 4,7 trimestres e da expansão era de 14,3 trimestres.

Segundo Hamilton (1989), a aplicação do modelo autorregressivo com mudança de regime markoviano a uma única série temporal, a taxa de crescimento do PNB real, gerou uma datação dos ciclos de negócios muito semelhante à datação feita pelo NBER, o que indica que essa metodologia poderia ser adotada nas projeções dos ciclos de negócios e na construção da cronologia desses ciclos. Não por acaso, a abordagem proposta por Hamilton (1989) tornou-se uma referência na literatura, e, em virtude disso, Chauvet e Hamilton (2006) afirmam que durante a década de 90 os pesquisadores acadêmicos passaram a investigar a datação das recessões por meio de uma abordagem estatística formal em vez de utilizarem uma avaliação qualitativa subjetiva.

De todo modo, essa literatura subsequente buscou estender a abordagem de Hamilton (1989) ao relaxar certas hipóteses restritivas. Por exemplo, Krolzig (1997) analisa o PIB alemão durante o período de 1960 a 1994, permitindo que a variância, além da média, dependa do regime da economia. Isso significa que o termo de erro do modelo é tal que $u_{t} \sim i i d N\left(0, \sigma^{2}\left(s_{t}\right)\right)$. Ainda, Boldin (1996), ao investigar o caso norte-americano, permite que a economia tenha mais do que dois regimes e obtém resultados favoráveis a um modelo com três regimes, a saber, recessão, expansão normal e expansão rápida. Essas extensões são consideradas no presente estudo.

\subsection{Artigos Correlatos}

Utilizando a abordagem de Hamilton (1989), Correa (2003) analisa os ciclos econômicos do Brasil e da Argentina no período de 1900 a 2000 e relata que a classificação em apenas dois regimes de negócios, recessão e expansão, são insuficientes para captar as diferentes intensidades do crescimento econômico desses dois países. Dessa forma, o autor sugere uma classificação em três regimes observáveis: recessão, estagnação e crescimento moderado ou acelerado. Finalmente, os resultados obtidos por Correa (2003) indicam diferenças marcantes entre os ciclos econômicos do Brasil e da Argentina. Enquanto a economia brasileira apre- 
sentou taxas de crescimento elevadas nos regimes de expansão, os períodos recessivos foram mais severos na Argentina. Em trabalho posterior, Correa e Hillbrecht (2004) incluem na análise os Estados Unidos e seus resultados indicam, mais uma vez, que as especificações compostas por três regimes são mais adequadas. Finalmente, os resultados referentes ao Brasil e à Argentina são semelhantes aos de Correa (2003). Já em relação aos Estados Unidos, foi possível perceber uma modificação nas características das flutuações a partir da Segunda Guerra Mundial, havendo uma redução da volatilidade. ${ }^{4}$

Especificamente para o Brasil, também se pode destacar o trabalho de Céspedes, Chauvet e Lima (2006), que estima modelos com mudança de regime markoviano para a série trimestral do PIB brasileiro para o período de 1975/1 a 2000/2, permitindo quebras estruturais nos Planos Collor. Os autores argumentam que a especificação MS-AR(2) apresenta o melhor ajuste para o ciclo econômico brasileiro. Ademais, no regime de recessão estima-se uma taxa de crescimento médio de -1,4\% a -1,5\% por trimestre, e no regime de expansão essa taxa varia de 1,6\% a 1,7\% por trimestre. Finalmente, enquanto recessões no Brasil duram, em média, de dois a três trimestres, as expansões duram, em média, de quatro a sete trimestres.

Medeiros e Sobral (2007) mostram que a modelagem MS-VAR com probabilidades de transição variáveis no tempo é capaz de identificar os diferentes estados do crescimento do PIB brasileiro no período de janeiro de 1995 a fevereiro de 2006. Na expansão estima-se uma taxa de crescimento média de cerca de $0,30 \%$ por mês, enquanto na recessão a taxa é aproximadamente de - $0,58 \%$ por mês, sendo que os períodos de contração não persistem por mais de dez meses.

Vieira e Pereira (2014) estudam os ciclos do PIB trimestral do Brasil, no período de 1900 a 2002, por meio de um modelo com mudança de regime markoviano que envolve uma correção Garch para heterocedasticidade. Os resultados indicam que, no período sob análise, houve expansão em 270 trimestres e recessão em 179 trimestres e que as estimativas das probabilidades de mudança entre os regimes identificam que, dado que a economia está em um regime, seja de expansão ou recessão, há uma maior probabilidade de permanecer no mesmo regime.

Há ainda na literatura estudos empíricos sobre os estados brasileiros, como o de Morais e Portugal (2003), que analisa a produção industrial regional trimestral, entre 1981 e 2001, por meio de modelo de mudança de regime. No caso do Rio Grande do Sul, os resultados da estimação do modelo MSMH-AR(0) indicam que: a) na expansão, a taxa de crescimento trimestral média é de 0,881 e, na recessão, torna-se $-0,405 ;$ b) a probabilidade do estado permanecer no estado em que já se encontra, recessão ou expansão, é maior do que a de mudar de estado; c) as expansões estendem-se no máximo por sete trimestres, enquanto as recessões atin-

4 De fato, há um consenso de que, a partir dos anos 1980, a economia norte-americana experimentou uma redução na volatilidade dos ciclos de negócios, o que é conhecido como great moderation. 
gem no máximo seis trimestres. Finalmente, vale destacar que Morais e Portugal (2003) fazem uma análise visual da evolução da produção industrial, tendo em mente a implementação de diversos planos econômicos (Cruzado I e II, Verão I e II, Collor I e II e Real). No presente trabalho, se dá um passo adiante ao empregar um modelo econométrico para investigar conexões entre políticas econômicas e a performance da indústria gaúcha.

Morais e Portugal (2007) estimam o modelo de fator dinâmico não linear a fim de verificar a existência de assimetria nos ciclos de negócios da indústria de transformação do Rio Grande do Sul no período de janeiro de 1992 a março de 2003. Os autores concluíram que a duração média da expansão é de 2,21 meses e da recessão é de 5,18 meses, sendo que a estimativa das probabilidades de transição mostra que a probabilidade de a indústria continuar em recessão é maior do que a probabilidade de continuar em expansão. Já Morais (2013) contrasta três diferentes técnicas de datação de ciclos de negócios na indústria do Rio Grande do Sul: a) identificação de recessões se ocorrerem duas quedas consecutivas do PIB real trimestral ou em outros indicadores do nível de atividade, como a produção industrial; b) utilização da metodologia de Bry e Boschan; c) aplicação do modelo de Hamilton (1989). Para estimarem o modelo de Hamilton (1989), os autores consideraram o período de 1996 a 2008, sendo excluído o período de grande volatilidade dos dados anterior ao Plano Real. Os resultados mostram que a produção setorial tem taxa de crescimento média de 3,2\% ao trimestre nas expansões e taxa média de 1,36\% ao trimestre nos períodos recessivos, ao passo que, em média, uma recessão no estado dura aproximadamente 2,6 trimestres e uma expansão, 2,1 trimestres. Outro resultado encontrado é a existência de assimetria na transição entre o ciclo de expansão e o de recessão, com maior probabilidade de se manter em um ciclo, dado que a economia já se encontra nele. Além disso, há uma maior probabilidade média de estar em um ciclo expansivo e passar para recessivo do que passar de uma recessão para uma expansão.

Por fim, destaca-se que o diferencial deste estudo consiste em investigar se as políticas econômicas afetam a recuperação ou a estagnação da economia do estado, além de identificar, considerando o período mais recente, os períodos em que o Rio Grande do Sul esteve em expansão ou recessão com base em extensões da abordagem proposta por Hamilton (1989).

\section{Políticas Econômicas e a Economia Gaúcha}

Nesta seção apresenta-se uma breve descrição das políticas econômicas adotadas no período de 2002 a 2016, da evolução de variáveis macroeconômicas importantes e das características da economia gaúcha. 


\subsection{Políticas Econômicas no Brasil}

É importante apresentar uma visão geral de como as políticas econômicas foram conduzidas no Brasil ao longo do período analisado (2002 a 2016), a fim de elucidar os seus possíveis impactos sobre os ciclos de negócios da indústria do Rio Grande do Sul. Para tanto, discutem-se as políticas e apresenta-se a evolução de importantes variáveis macroeconômicas.

O primeiro ano da nossa amostra, 2002, é marcado por turbulências externas e internas. Houve uma desaceleração das economias norte-americanas e mundial, e, além disso, a incerteza política devido às eleições presidenciais suscitou preocupações quanto ao controle da inflação. Todo esse cenário, somado a oito anos seguidos de elevação da relação dívida pública/PIB, teve grande impacto nas políticas econômicas implementadas pelo governo brasileiro (GOMES; AIDAR, 2005). Em 2003, a política monetária passou a ser mais restritiva (a taxa de juros aumentou), a política fiscal também foi restritiva (maior superávit primário) e, nesse contexto, houve uma redução da taxa de câmbio (SILVA; PIRES; TERRA, 2014).

Em 2004, o país passou por um crescimento considerável decorrente de um grande ajuste externo que teve início em 1998. Neste ano, o país passou por uma crise de balanço de pagamentos e, não por acaso, em 1999 o câmbio deixou de ser fixo. Desde então houve uma desvalorização do real, ainda que ocorressem reversões em certos períodos, como em 2003. Finalmente, o Brasil passou a experimentar grandes aumentos nas exportações de bens (BRESSER-PEREIRA; GOMES, 2009). Não por acaso, a manutenção da alta taxa de juros pelo Banco Central e o aumento das exportações gerou uma redução da taxa de câmbio a partir de meados de 2004 (ver Figura 1), o que propiciou uma redução da taxa de inflação.

Figura 1 - Brasil: taxa de câmbio nominal (\% a. m.)

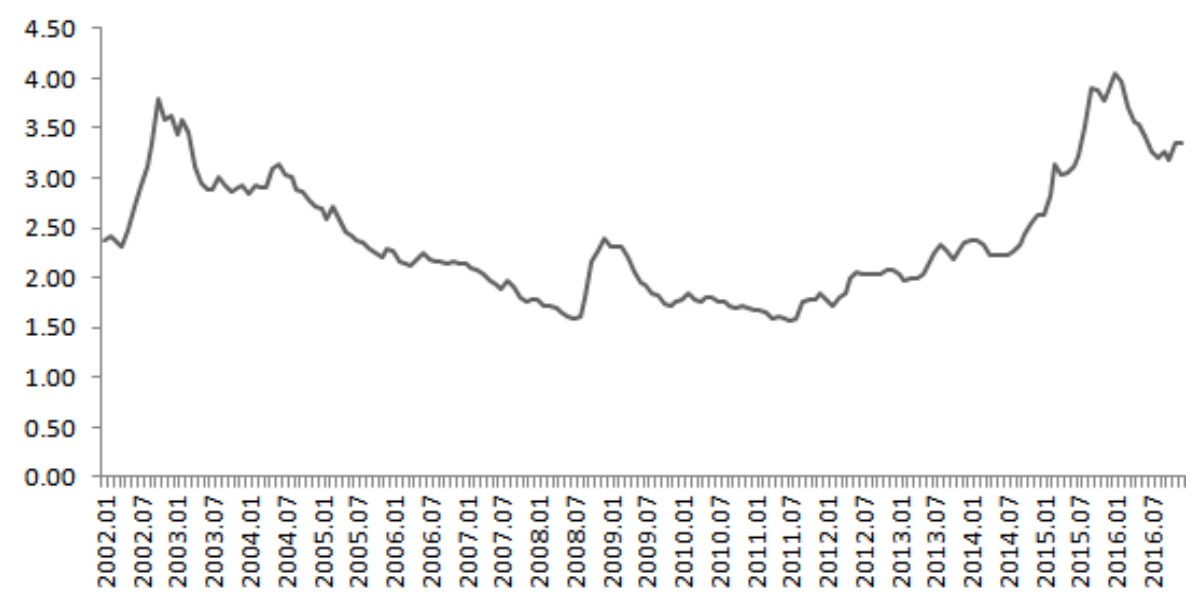

Fonte: Banco Central do Brasil, (2017). 
No ano de 2005, o Banco Central aumentou novamente a taxa de juros, acentuando o compromisso do Comitê de Política Monetária (Copom) de evitar que a inflação se desviasse da trajetória prevista para atingir a meta de inflação (ver Figura 2). Ao longo de 2006, à medida que as expectativas de inflação começaram a declinar, o Copom afrouxou a política monetária por meio da redução da taxa de juros e, assim, conseguiu, além da estabilidade dos preços, incentivar o crescimento econômico (BEVILAQUA, 2015).

Figura 2 - Brasil: taxa de juros real/Selic (\% a. m.)

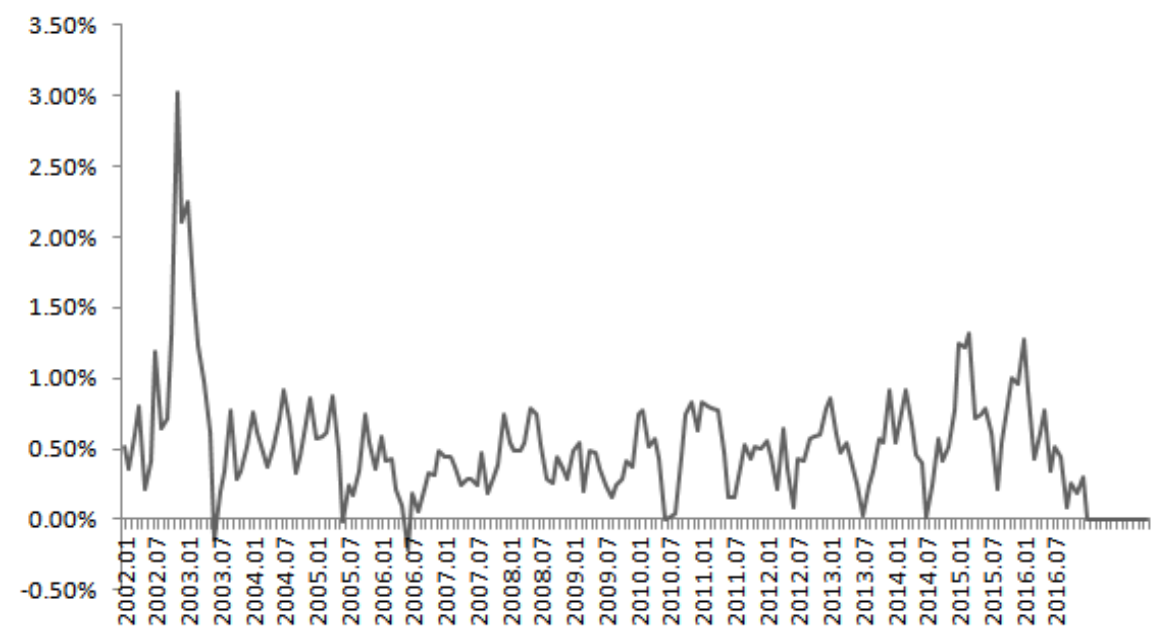

Fonte: Banco Central do Brasil (2017).

A crise financeira mundial de 2008 afetou negativamente a produção industrial e o PIB brasileiro e causou uma mudança na condução da política econômica do país. O novo cenário fez com que o governo reduzisse a taxa básica de juros e adotasse uma política fiscal mais expansionista, com aumento dos gastos do governo federal. Nesse contexto, houve uma desvalorização do real. Ademais, foi feito um aumento das linhas de financiamento dos bancos públicos para suprir a falta de crédito gerada pela deterioração dos mercados financeiros. Portanto, o governo implementou políticas anticíclicas para tentar recuperar a economia brasileira (ARAÚJO; GENTIL, 2011).

Após a desvalorização do real ocasionada pela crise de 2008, a moeda brasileira se valorizou entre 2009 e 2010. Posteriormente, tem-se uma trajetória de aumento da taxa de câmbio, ocasionada pelo aumento dos prêmios de risco, temores em relação à dinâmica da dívida pública e incapacidade do governo em reequilibrar suas contas no curto prazo.

A política monetária voltou a ser restritiva, com elevação da taxa de juros, após meados do ano de 2014. No entanto, em 2016, o Copom reduziu a taxa de ju- 
ros, que, ao contribuir para o aumento da confiança dos investidores e a redução dos juros bancários, poderia estimular a economia brasileira. Destaca-se também que, em 2015, a taxa de câmbio aumentou consideravelmente, embora tenha recuado em 2016.

A Figura 3 apresenta a evolução da dívida pública do governo federal e do governo estadual, permitindo que se identifiquem pontos de inflexões na política fiscal, já comentados. Em particular, a dívida referente ao governo federal mostra uma inflexão importante em meio à crise internacional em 2009. A crise em si causa uma redução da arrecadação, de modo que, mesmo que o governo não aumente seus gastos, há uma tendência de aumento da dívida. Porém, de fato nesse período a política fiscal foi anticíclica. Houve crescimento dos gastos e desonerações que levaram à diminuição do superávit primário e à elevação da dívida pública. A dívida líquida do governo federal apresentava tendência à queda até essa inflexão e, posteriormente, voltou a sua tendência de redução. Em 2015, na ausência de superávits primários, percebe-se um crescimento da dívida líquida relacionado principalmente com as despesas de juros (FERREIRA; FRAGELLI, 2015).

Figura 3 - Brasil: dívidas líquidas dos setores públicos dos governos federal e estadual (\% PIB)

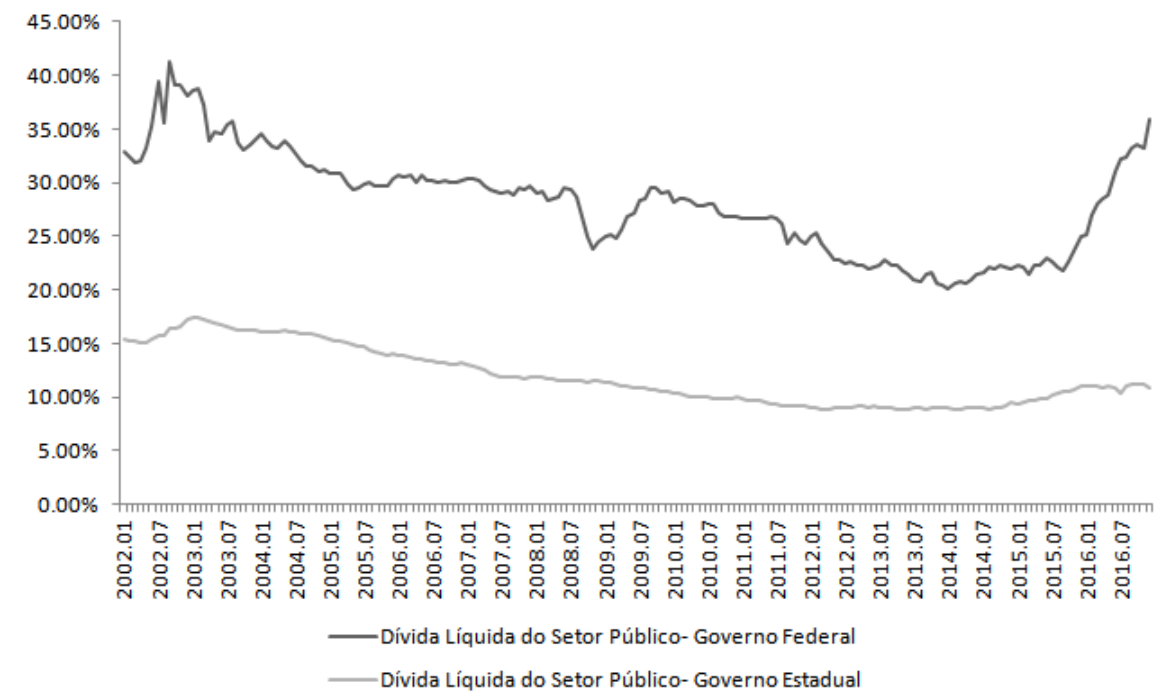

Fonte: Banco Central do Brasil (2017).

Já em relação à dívida líquida do governo estadual, durante muitos anos o Rio Grande do Sul utilizou endividamento público para financiar seus déficits orçamentários. Em 1997, houve uma renegociação da dívida do estado para que as finanças estaduais não se degradassem. No entanto, como o Rio Grande do Sul 
não conseguiu pagar nem mesmo o suficiente para cobrir os juros da dívida, o saldo devedor da dívida apenas aumentou. Em 2014, 86,1\% do total da dívida do estado era devido ao Programa de Apoio à Reestruturação e ao Ajuste Fiscal dos Estados (CALDAS et al., 2015). A fim de tentar manter as contas estáveis, as autoridades recorreram a empréstimos, privatizações, venda de patrimônio, saques do caixa único e depósitos judiciais. Ademais, para combater essa situação o governo focou no corte de gastos (Figura 3). Desse modo, é possível ver que a dívida segue uma trajetória decrescente ao longo de praticamente todo o período analisado e não acompanhou o ponto de inflexão da dívida do governo federal relacionado à crise de 2009.

\subsection{Características Econômicas do Rio Grande do Sul}

Os dados disponíveis pela Fundação de Economia e Estatística Siegfried Emanuel Heuser (FEE) indicam que, em 2014, o Rio Grande do Sul retomou a posição de quarta maior economia do país. De acordo com Cargnin et al. (2014), a importante participação desse estado na economia nacional é devido à centralidade exercida pelos estados da região Sudeste, com quem a economia gaúcha apresenta uma associação superior à média brasileira.

Segundo Morais (2013), apesar da diversificação da indústria do estado em segmentos, produtos e mercados, percebe-se forte presença das categorias de bens de capital e de consumo durável, ambos muito dependentes da renda, do volume de crédito e da taxa de juros. Além disso, as atividades agroindustriais, com destaque para as exportações de commodities, conjuntamente com exportadores industriais fazem com que os resultados econômicos do estado estejam sujeitos às variações da economia global e da taxa de câmbio.

A Figura 4 apresenta a estrutura da produção por atividade econômica no Rio Grande do Sul. Nota-se que, no período analisado, não houve grandes oscilações na importância relativa dos três setores de atividade, sendo que as exceções ocorreram nos anos de 2005 e 2012, quando o setor agropecuário sofreu queda devido à estiagem que provocou perdas das safras no estado. De acordo com Fochezatto e Grando (2011), a piora no desempenho da agropecuária impacta o PIB estadual, pois está fortemente interligada a outros setores da sua matriz produtiva, como, por exemplo, o milho, que é um componente importante da ração animal que faz parte do segmento de carnes, sendo este considerável nas exportações do estado. 
Figura 4 - Rio Grande do Sul: participação dos setores de atividade no valor adicionado bruto

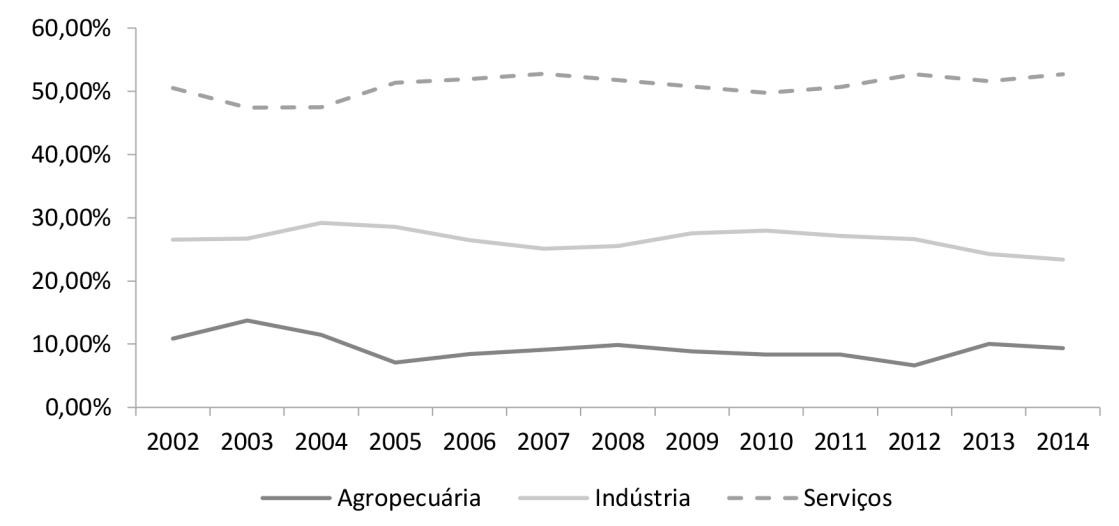

Fonte: IBGE (2017).

Na Figura 4 podemos observar, também, uma maior participação do setor de serviços no período de 2002 a 2014, cujas principais atividades incluem comércio, atividades imobiliárias e de alojamento e alimentação (RISCO, 2017). De acordo com Cargnin et al. (2014), além da participação do comércio nesse segmento, a abertura econômica vivenciada nas últimas décadas acabou ocasionando um aumento de instalações de empresas no estado, em especial nos segmentos de serviços de transporte, informação e comunicação, logística, consultoria e manutenção e equipamentos. Ademais, a administração pública também se insere nesse setor e aumentou sua participação com base na universalização de serviços como os de saúde e de educação.

Além da importância da agropecuária para a economia do estado, deve-se destacar o papel da indústria de transformação. Segundo Feix, Leusin Jr. e Agranonik (2016), a indústria de máquinas e equipamentos contribui com aproximadamente $12 \%$ do valor da transformação da indústria gaúcha, sendo que os produtos dos segmentos de fabricação de bens de capital para a agropecuária (tratores agrícolas, colheitadeiras e plantadeiras) são responsáveis por mais da metade desse valor. Percebe-se, então, que, apesar de não ser o setor predominante no valor adicionado bruto do estado, sua atividade incentiva o dinamismo das regiões e gera crescimento da renda (CARGIN et al., 2014).

Em relação ao setor exportador, Cargin et al. (2014) mostram que a desvalorização da moeda brasileira ampliou as opções de exportação do Rio Grande do Sul, em especial nos setores de agroindústria. Por sua vez, em períodos de valorização do real, as dificuldades aumentaram, com destaque no setor de calçados, que passou a concorrer com preços baixos de outros países. 
Após o forte arrefecimento dos preços das commodities, a partir do final de 2012 e com maior intensidade desde o final de 2014, os preços em dólar dos produtos exportados pelo Rio Grande do Sul iniciaram uma recuperação gradual ao longo de 2016 devido à recuperação dos preços dos produtos básicos de commodities importantes para o estado, como a soja em grãos e o fumo em folhas. Atualmente, metade de toda a receita exportadora gaúcha é proveniente da venda de cinco produtos: soja em grãos $(22,8 \%)$, fumo em folhas $(9,6 \%)$, carne de frango $(6,3 \%)$, polímeros plásticos $(6,1 \%)$ e farelo de soja (5,3\%) (TOREZANI, 2016). Portanto, ao se analisar a dinâmica das atividades econômicas do estado, observa-se que, em relação ao setor exportador, há uma predominância da agroindústria. Feix, Leusin Jr. e Agranonik (2016) mostram que parte significativa da produção agropecuária do estado é exportada na forma de matéria-prima ou de alimentos processados, sendo a China o principal comprador, tendo absorvido mais de um terço das exportações do setor em 2015.

Finalmente, mesmo com grande participação do setor de serviços no valor adicionado bruto, o setor agropecuário e a indústria de transformação afetam de modo significativo a economia do Rio Grande do Sul, sendo que esses setores apresentam modificações nos seus desempenhos provenientes de eventos relacionados com desequilíbrio na balança comercial, mudança da taxa de câmbio, medidas protecionistas adotadas pelos países importadores, eventos de estiagens periódicas ou safras acima da média (CARGIN et al., 2014).

\section{Metodologia Empírica}

Na seção 4.1 é descrita a base de dados utilizada, o que inclui a medida do nível de atividade e as variáveis macroeconômicas de interesse. Na seção 4.2 são apresentados os modelos autorregressivos com mudança de regime de Markov e os modelos usados para confrontar os ciclos de negócios e as variáveis de política econômica.

\subsection{Base de dados}

Este trabalho utiliza uma base de dados mensal, de janeiro de 2002 a dezembro de 2016, coletada dos sites do Banco Central do Brasil e do IBGE.

A medida do nível de atividade econômica utilizada é o logaritmo da produção industrial do estado do Rio Grande do Sul, fornecida pela Pesquisa Industrial Mensal - Produção Física (PIM-PF). A evolução do número-índice com ajuste sazonal da produção industrial e a sua taxa de crescimento são apresentados, respectivamente, nas Figuras 5 e 6. 
Figura 5 - Rio Grande do Sul: índice de base fixa com ajuste sazonal (base: média de $2012=100)$

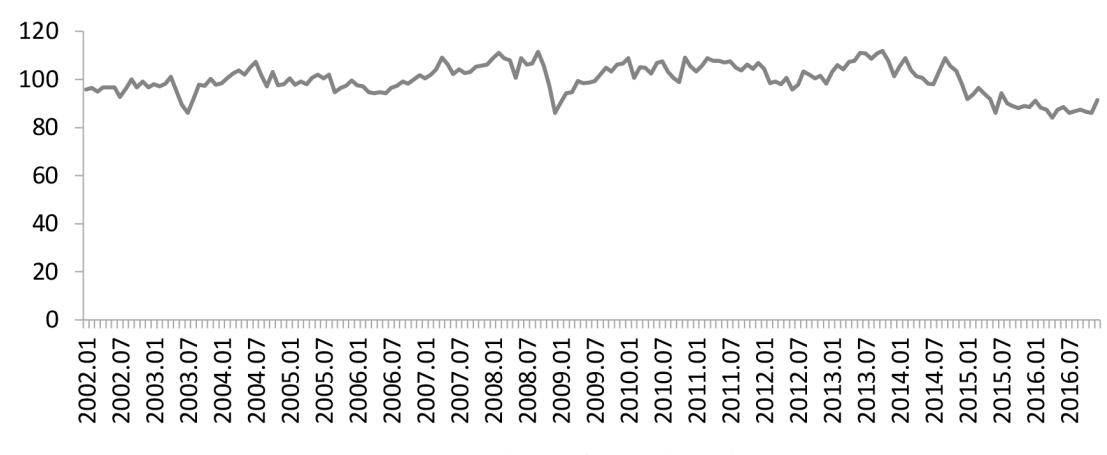

—Produção Física Industrial

Fonte: IBGE (2017).

Figura 6 - Rio Grande do Sul: taxa de crescimento

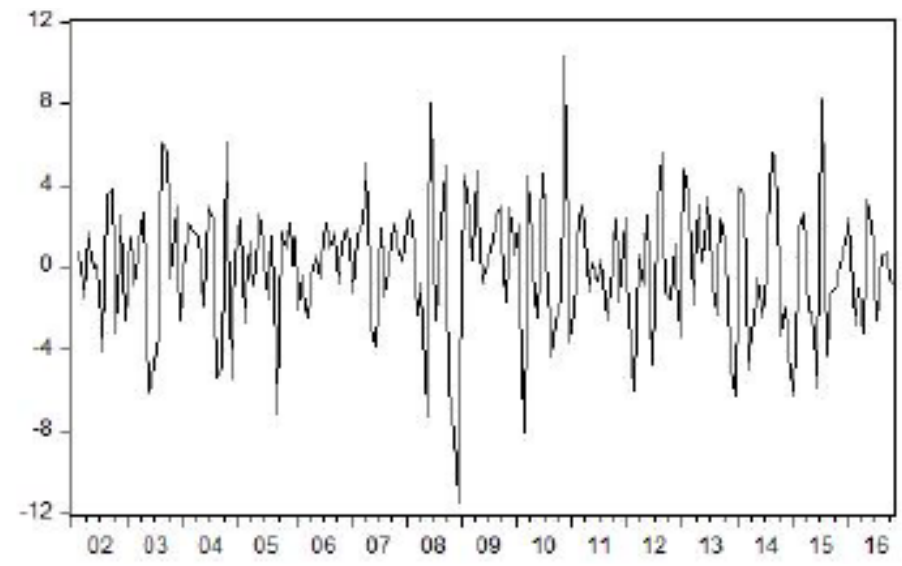

Fonte: Elaboração própria a partir de dados da PIM-PF do IBGE (2017).

Alguns pontos merecem destaque. Primeiramente, nota-se na Figura 5 que não há uma tendência na produção industrial nesse período, sendo o nível de atividade em 2002 muito semelhante ao de 2016. No entanto, isso não significa que a produção industrial se manteve estável nesse período. De fato, a Figura 6 mostra que a taxa de crescimento da produção industrial experimentou considerável oscilação ao longo do período sob análise e, desse modo, a indústria passou por diversos períodos de expansão e de recessão.

Em 2003, observa-se uma queda na produção industrial, ano em que houve um aumento na taxa de juros devido à opção por uma política monetária mais restri- 
tiva para combater a inflação. Nesse mesmo ano a taxa de câmbio ainda estava em um patamar elevado, o que significa que os produtos importados, inclusive insumos, estavam caros. A melhora posterior da produção industrial pode estar atrelada à melhora da economia do país, após um ajuste externo e um aumento das exportações. Em 2005 percebe-se outra redução da produção, ano em que houve novamente um aumento da taxa de juros. Já em 2006, com a modificação da política monetária, a redução da taxa de juros incentivou o aumento da produção. Ademais, nota-se na Figura 6 que a queda mais acentuada da produção industrial se deu durante a crise financeira internacional em 2008. Para recuperar a economia, o governo adotou políticas anticíclicas: redução da taxa de juros e aumento do gasto público. Além disso, ocorreu uma desvalorização do real. Mais recentemente, a partir de 2014, o país entrou em um cenário de crise e a produção industrial evidencia isso.

A Tabela 1 apresenta as taxas de crescimento da produção industrial. A taxa média de crescimento dos 179 meses da amostra é de -0,0003\% ao mês, o que implica uma taxa de crescimento anual de $-0,0036 \%$. Como o que aqui interessa é estudar períodos de recessão e de expansão, a Tabela 1 apresenta também a taxa de crescimento média dos 94 meses que tiveram crescimento positivo e dos 85 meses que tiveram crescimento negativo. No primeiro caso, a taxa de crescimento médio é de $0,0253 \%$ ao mês e no segundo caso -0,0285\%. Como essas duas taxas são semelhantes, em módulo, assim como o número de meses com crescimento e decrescimento, a produção industrial permaneceu estável no período de 2002 a 2016, como já mencionado. A Tabela 1 apresenta, ainda, os desvios padrões referentes a todos os meses da amostra $(0,0343)$, aos meses de crescimento $(0,0197) \mathrm{e}$ aos meses de decrescimento $(0,0229)$. Há uma indicação inicial de que não deve ser feita a hipótese de homocedasticidade do termo de erro do modelo (2).

Tabela 1 - Estatística descritiva: taxa de crescimento do produto industrial

\begin{tabular}{cccc}
\hline Estatística & $\begin{array}{l}\text { Taxa de cres- } \\
\text { cimento }\end{array}$ & $\begin{array}{l}\text { Taxa de cresci- } \\
\text { mento positiva }\end{array}$ & $\begin{array}{l}\text { Taxa de crescimento } \\
\text { negativa }\end{array}$ \\
\hline Número de meses & 179 & 94 & 85 \\
Média (\% a. m.) & $-0,0003$ & 0,0253 & $-0,0285$ \\
$\begin{array}{c}\text { Desvio padrão (\% } \\
\text { a. m.) }\end{array}$ & 0,0343 & 0,0197 & 0,0229 \\
\hline
\end{tabular}

Nota: $y_{t}$ é o logaritmo da produção industrial; a taxa de crescimento é calculada como $\Delta y$; na segunda coluna, as estatísticas são calculadas com base nos 179 meses da amostra; na terceira (quarta) coluna, são considerados apenas os meses nos quais $\Delta y_{t}>0\left(\Delta y_{t}<0\right)$. 
Com o intuito de se analisar os efeitos das políticas econômicas sobre a indústria do Rio Grande do Sul, são consideradas as seguintes variáveis: taxa de juros real ao mês (taxa de juros nominal Selic over mensal deflacionada pelo IPCA) e as dívidas líquidas como percentual do PIB dos governos federal e estadual. Além disso, foram incluídas nas análises econométricas a média mensal da taxa de câmbio nominal (real/dólar). As Figuras 1 a 3 já apresentaram a evolução dessas variáveis. Como usual, averiguou-se a ordem de integração dessas variáveis por meio dos testes de raiz unitária Dickey-Fuller aumentato (ADF) e Philips-Perron (PP). ${ }^{5} \mathrm{~A}$ Tabela 2 mostra o resultado de ambos os testes. Os testes ADF e PP indicam que, aos níveis de significância usuais, apenas a taxa de juros é integrada de ordem zero. Nos demais casos, há evidência favorável à hipótese nula de raiz unitária.

Tabela 2 - Testes de raiz unitária: séries em nível

\begin{tabular}{|l|c|c|}
\hline \multirow{2}{*}{ Séries em nível } & \multicolumn{2}{|l|}{ Estatística de teste } \\
\cline { 2 - 3 } & ADF & PP \\
\hline Dívida líquida do governo federal & 0,1458 & $-0,0321$ \\
\hline Dívida líquida do governo estadual & $-0,8199$ & $-0,0066$ \\
\hline Taxa de câmbio nominal & 0,1116 & 0,1304 \\
\hline Taxa de juros real & $-5,3669 * * *$ & $-5,5090 * * *$ \\
\hline
\end{tabular}

Nota: No caso do teste ADF, o número de defasagens da variável dependente incluídas na equação de teste foi definido com base no critério de informação de Schwarz, sendo considerada a defasagem máxima igual a 12. No caso do teste PP, foi usada a janela de NeweyWest e o núcleo de Bartlett. Inicialmente, em ambos os testes as equações de teste incluíram uma constante e uma tendência linear que, quando não significativas a 10\%, foram excluídas. *******" indicam significância a 1\%, $5 \%$ e 10\%, respectivamente.

Como no caso das séries dívida líquida do governo federal, dívida líquida estadual e taxa de câmbio não foi rejeitada a hipótese nula de raiz unitária, tomou-se a primeira diferença de tais séries e aplicaram-se novamente os testes de raiz unitária. Os resultados são apresentados na Tabela 3 e indicam, aos níveis de significância usuais, que em primeira diferença tais variáveis são integradas de ordem zero. Portanto, conclui-se que basta diferenciá-las uma única vez, antes de estimar os modelos econométricos que visam relacionar os ciclos de negócios da indústria gaúcha e as políticas econômicas.

$5 \quad$ Para mais detalhes, ver Dickey e Fuller (1979) e Phillips e Perron (1988). 
Tabela 3 - Testes de raiz unitária: séries em primeira diferença

\begin{tabular}{|c|l|l|}
\hline \multirow{2}{*}{ Séries em primeira diferença } & \multicolumn{2}{|l|}{ Estatística de teste } \\
\cline { 2 - 3 } & ADF & PP \\
\hline Dívida líquida do governo federal & $-14,9093 * * *$ & $-14,9564 * * *$ \\
\hline Dívida líquida do governo estadual & $-4,3778^{* * *}$ & $-12,4641 * * *$ \\
\hline Taxa de câmbio nominal & $-9,3373 * * *$ & $-9,5114 * * *$ \\
\hline
\end{tabular}

Nota: No caso do teste $\mathrm{ADF}$, o número de defasagens da variável dependente incluídas na equação de teste foi definido com base no critério de informação de Schwarz, sendo considerada a defasagem máxima igual a 12. No caso do teste PP, foi usada a janela de Newey-West e o núcleo de Bartlett. Inicialmente, em ambos os testes as equações de teste incluíram uma constante que, quando não significativas a 10\%, foi excluída. ******", indicam significância a 1\%, 5\% e $10 \%$, respectivamente.

\subsection{Modelos Econométricos}

Este trabalho utiliza o modelo autorregressivo univariado com mudanças de regime markoviano, permitindo que não somente a média, mas também a variância da taxa de crescimento do produto industrial dependa do estado da economia. Portanto, diferentemente do trabalho de Hamilton (1989), considera-se a possibilidade de haver heterocedasticidade. Como os dados têm frequência mensal, o modelo inicial é composto por 12 defasagens $(p=12)$. Além disso, são considerados os casos com dois e três regimes, $n=2,3 \cdot y_{\mathrm{t}}$ e $\Delta y_{\mathrm{t}}$ são, respectivamente, o logaritmo do produto industrial do Rio Grande do Sul e sua taxa de crescimento. Desse modo, considera-se inicialmente o seguinte modelo:

$$
\Delta y_{t}-\mu\left(s_{t}\right)=\alpha_{1}\left(\Delta y_{t-1}-\mu\left(s_{t-1}\right)\right)+\cdots+\alpha_{12}\left(\Delta y_{t-12}-\mu\left(s_{t-12}\right)\right)+u_{t}
$$

em que $u_{t} \sim$ iid $N\left(0, \sigma^{2}\left(s_{t}\right)\right)$, ora com, ora com $s_{t}=\{1,2,3\}$. Há 12 parâmetros autorregressivos, $\alpha_{1}, \ldots, \alpha_{12}$. Com $n=2$, no regime um tem-se a taxa de crescimento média $\mu_{1}$ e a variância $\sigma_{1}^{2}$, enquanto, no regime dois, esses parâmetros tornam-se $\mu_{2}$ e a variância, $\sigma_{2}^{2}$. Naturalmente, com $n=3$ tem-se três parâmetros distintos para a taxa média de crescimento e para a variância.

A estimação do modelo de mudança de regime markoviano pode ser realizada por máxima verossimilhança usando-se o filtro de Hamilton, o filtro de Kalman ou o algoritmo expactation-maximization (EM). Por meio do programa E-views 9, utilizou-se o filtro de Hamilton.

Como o estado da economia não é observado, é necessário fazer inferência após a estimação do modelo 3 com respeito a esse estado. Em outras palavras, para cada período estima-se a probabilidade de a economia estar em recessão e 
a probabilidade de estar em expansão, no caso com dois regimes. Se a especificação selecionada for composta por três regimes, três probabilidades são estimadas. Como o objetivo aqui é analisar a relação dos ciclos de negócios com variáveis de política econômica, essas probabilidades são estimadas fazendo-se uso de toda a informação contida na amostra, ou seja, estimam-se probabilidades suavizadas.

Considerando-se o caso com dois regimes, uma vez obtidas as probabilidades de recessão para cada período da amostra, procede-se a datação dos ciclos econômicos de forma imediata: quando a probabilidade de recessão é superior a 50\%, considera-se que a economia está em recessão. Feita a datação dos períodos de recessão e de expansão, investiga-se a relação entre o estado da indústria gaúcha e as variáveis que são proxies para as políticas econômicas. Para tanto, considera-se o seguinte modelo:

$$
\ln \left(C_{t}\right)=\beta_{0}+\rho \ln \left(C_{t-1}\right)+\sum_{k=1}^{K} \sum_{l=1}^{L} \beta_{k, l} x_{k, t-l}+\varepsilon_{t}
$$

em que $\ln \left(C_{t}\right)$ é o logaritmo natural da chance de a indústria gaúcha estar em estado de recessão no período $t$, isto é, $C_{t}=\operatorname{Pr}\left[R_{t}\right] /\left(1-\operatorname{Pr}\left[R_{t}\right]\right)$, sendo $\operatorname{Pr}\left[R_{t}\right] \mathrm{a}$ probabilidade (suavizada) de a economia estar em recessão no período $t .{ }^{6}$ As variáveis dependentes incluem a própria defasagem da variável dependente, além de $l$ defasagens de $k$ variáveis que são proxies para as políticas econômicas, a saber a taxa de juros, a dívida federal, a dívida estadual. Além disso, consideram-se também defasagens da taxa de câmbio. A linearidade do modelo 4 permite que sua estimação seja feita por meio do método MQO. A estimativa do parâmetro $\rho$ nos informa sobre a persistência da chance de recessão, e as estimativas dos parâmetros $\beta_{\mathrm{k}, \mathrm{l}}$ nos informam sobre a associação entre as variáveis macroeconômicas e a chance de ocorrer recessão.

O modelo 4 é estimado pelo método MQO com a correção de Newey-West para a matriz de variância e covariância dos coeficientes. Essa correção é robusta aos problemas de heterocedasticidade e correlação serial, sendo, por isso, adotada. Como a chance de ocorrer recessão é uma variável construída a partir do modelo de mudança de regime apresentado na equação (3), estimou-se o modelo 4 usando-se o método de bootstrap com o objetivo de se levar em conta no cálculo dos erros padrões a incerteza inerente à construção de $C_{t}$.

$6 \quad$ No caso com três regimes há duas possibilidades. Apenas um regime é de recessão, digamos com $\hat{\mu}_{1}<0, \hat{\mu}_{2}>0$ e $\hat{\mu}_{3}>0$. Porém, se há dois regimes de recessão, por exemplo, $\hat{\mu}_{1}<0, \hat{\mu}_{2}<0$ e $\hat{\mu}_{3}>0$, então podemos estudar separadamente as probabilidades associadas a recessões severas e recessões moderadas ou agregá-las. 


\section{Resultados}

Para a escolha da especificação adequada do modelo três estimou-se, inicialmente, 24 especificações, variando-se o número de termos autorregressivos de um a 12 e o número de regimes de dois a três. Feito isso, compararam-se os modelos bem especificados com base nos critérios de informação de Akaike e de Schwarz, sendo escolhido o modelo com dois regimes e quatro defasagens. ${ }^{7}$ Os resultados são apresentados na Tabela 4.

Tabela 4 - Resultados da estimação do modelo três

Variável dependente: taxa de crescimento da produção industrial.

Especificação: $n=2, p=4$, heterocedástico.

Amostra: fevereiro de 2002 a dezembro de 2016

Parâmetros constantes

\begin{tabular}{cccc}
$\alpha_{1}$ & $\alpha_{2}$ & $\alpha_{3}$ & $\alpha_{4}$ \\
$-0,2723^{* * *}$ & $-0,2594^{* * *}$ & $-0,0947$ & $-0,1675^{* *}$ \\
$(0,0782)$ & $(0,0749)$ & $(0,0725)$ & $(0,0810)$ \\
\hline
\end{tabular}

Parâmetros dependentes do regime

Regime 1: recessão

Regime 2: expansão

$\begin{array}{cccc}\mu_{1} & \ln \left(\sigma_{1}^{2}\right) & \mu_{2} & \ln \left(\sigma_{2}^{2}\right) \\ -0,0079^{* *} & -3,2003^{* * *} & 0,0077^{* * *} & -4,0086^{* * * *} \\ (0,0039) & (0,1185) & (0,0025) & (0,1848)\end{array}$

Probabilidades de transição

\begin{tabular}{cccc}
$p_{11}$ & $p_{12}$ & $p_{21}$ & $p_{22}$ \\
0,8145 & 0,1854 & 0,2037 & 0,7962 \\
\hline
\end{tabular}

Duração de cada regime (em meses)

Regime $1 \quad$ Regime 2

$5,393 \quad 4,907$

Nota: A duração de cada regime é calculada como $1 /\left(1-p_{11}\right)$ e $1 /\left(1-p_{22}\right)$. Entre parêntesis estão os erros padrões. ***, **, * indicam significância a 1\%, 5\% e 10\%, respectivamente.

Os coeficientes autorregressivos de primeira e segunda ordem são significativos a $1 \%$ e o de quarta ordem é significativo a $5 \%$. A terceira defasagem da taxa de crescimento não é relevante, mesmo ao nível de 10\% de significância. Quanto aos parâmetros específicos de cada regime, todos são estatisticamente diferentes de zero, a 5\% de significância. A taxa de crescimento

$7 \quad$ Por modelo bem especificado entende-se especificações cujo processo de otimização foi convergente, nas quais são identificados pelo menos dois regimes, isto é, com pelo menos duas taxas de crescimento médias significativas a $5 \%$ e com sinais opostos. 
média na recessão é $\hat{\mu}_{1}=-0,0079$ ao mês, enquanto na expansão a taxa média é $\hat{\mu}_{2}=0,0077$ ao mês. Em termos absolutos, tais taxas de crescimento são similares, o que está em linha com a estatística descritiva apresentada na Tabela 1. Tomando-se o exponencial do logaritmo das variâncias, obtêm-se $\hat{\sigma}_{1}^{2}=0,0407$ e $\hat{\sigma}_{2}^{2}=0,0182$. Por meio do teste de Wald, avaliou-se a hipótese nula $\ln \left(\sigma_{1}^{2}\right)=\ln \left(\sigma_{2}^{2}\right)$, obtendo-se um $p$-valor inferior a $1 \%$. Com isso, rejeita-se, aos níveis de significância usuais, que as variâncias sejam iguais. Em outras palavras, há evidência de que o modelo homocedástico não é apropriado.

Após a estimação do modelo três, investigaram-se as propriedades dos resíduos do modelo. Em particular, investigou-se se há correlação serial via análise do correlograma e aplicação do teste Ljung-Box. Foi investigada uma correlação serial de até sexta ordem, não sendo encontrada evidência desse problema, ao nível de significância de 5\%. De maneira análoga, investigou-se também o resíduo ao quadrado, e tanto o correlograma quanto o teste Ljung-Box indicaram ausência de heterocedasticidade, ao nível de significância de 5\%.

As probabilidades de transição, que informam as probabilidades de a economia continuar no mesmo regime ou mudar para o outro regime, são apresentadas na Tabela 4. Essas probabilidades indicam que, quando a indústria do Rio Grande do Sul está em um regime de recessão, a probabilidade de que o estado permaneça nesse regime é bastante elevada, de 0,8145, sendo inclusive superior à probabilidade de a economia continuar em uma expansão, de 0,7962 . Não por acaso, a duração média das recessões, de 5,393 meses, é superior à duração média das expansões, de 4,907 meses. Finalmente, tem-se que a probabilidade de a produção industrial passar de expansão para recessão, de 0,2037, é maior do que a probabilidade de mudar de um regime de recessão para expansão, de 0,1854.

Embora os estudos prévios de Morais e Portugal (2007) e Morais (2013) sobre o Rio Grande do Sul investiguem períodos distintos do nosso, ainda assim é possível realizar uma comparação da extensão das expansões e das recessões. No primeiro trabalho, os autores utilizam dados mensais referentes ao período de janeiro de 1992 a março de 2003 e encontram períodos de expansão com duração de 2,21 meses e 5,18 meses na recessão. Já no segundo estudo, a base de dados entre 1996 e 2008 foi trimestral, sendo 2,1 e 2,6 trimestres de expansão e recessão, respectivamente. Percebe-se, então, que os períodos de recessão dos outros trabalhos (5,18 meses e 2,1 trimestres) foram próximos dos encontrados neste estudo (5,39 meses), enquanto que as expansões foram diferentes, 2,21 meses e 2,6 trimestres contra 4,90 meses identificados neste trabalho. Ademais, destaca-se que em todos os casos os regimes de recessão foram mais longos do que os regimes de expansão.

A inferência sobre o estado da economia é feita com base nas probabilidades suavizadas, que são apresentadas para cada mês da amostra na Figura 7. Como 
usual, quando a probabilidade de ocorrência de recessão é superior a 50\% considera-se que a indústria gaúcha está em recessão.

Figura 7 - Rio Grande do Sul: probabilidades suavizadas

Recessāo

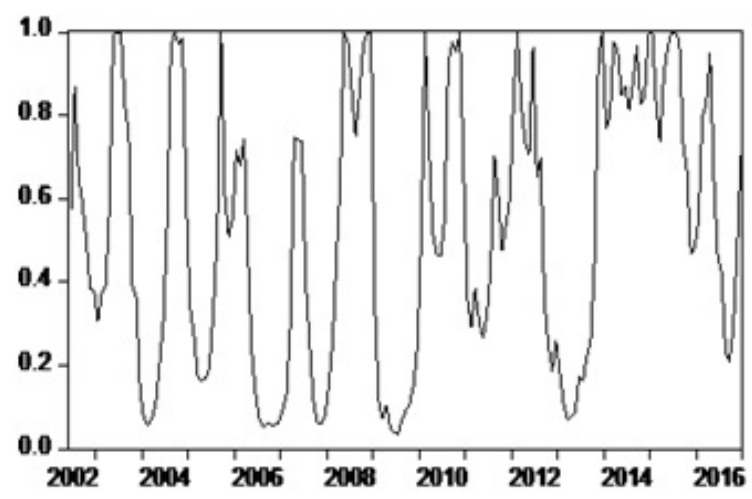

Expansāo

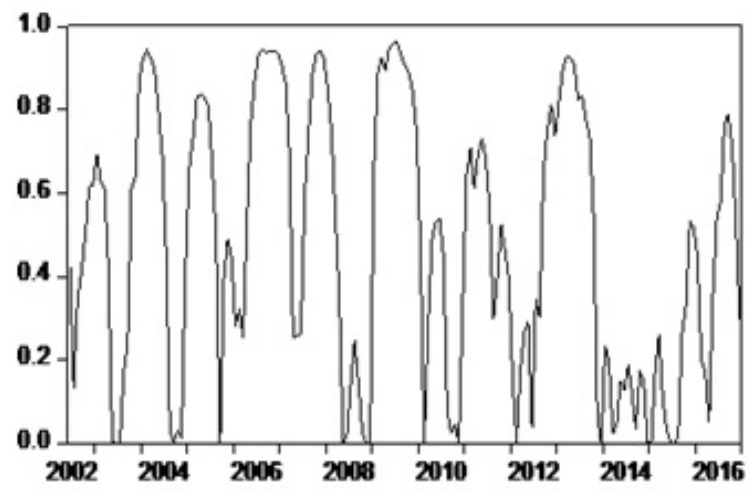

Fonte: Probabilidades provenientes da estimação do modelo (3)

Usando-se esse critério, apresenta-se, na Figura 8, a taxa de crescimento da produção industrial: as regiões hachuradas denotam os períodos de recessão, o que fornece uma visão geral do ciclo de negócios na indústria do Rio Grande do Sul no período de janeiro de 2002 a dezembro de 2016. A inspeção visual revela que os períodos datados como recessivos são marcados por pelo menos uma queda acentuada da produção industrial. Há uma recessão bastante longa de meados de 2013 ao início de 2015 marcada por elevada variância, ou seja, alternam-se quedas acentuadas e recuperações. 
Figura 8 - Taxa de crescimento da produção industrial do Rio Grande do Sul

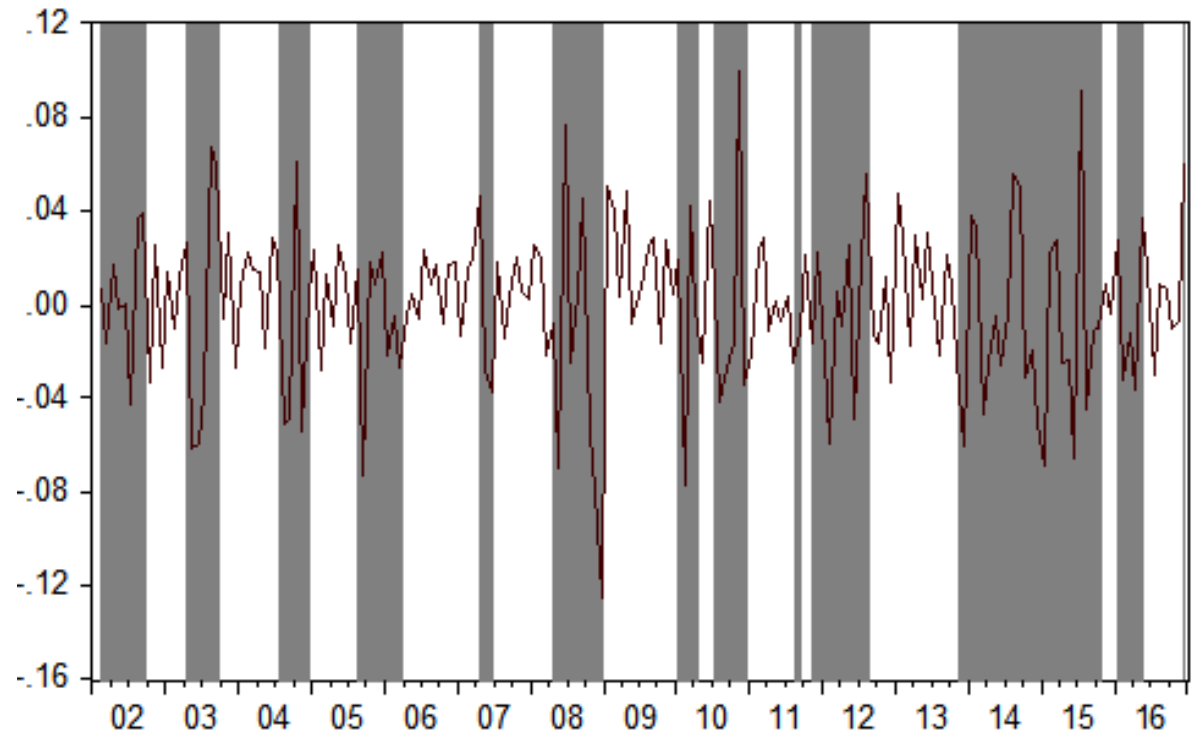

Fonte: Elaboração própria a partir de dados da PIM-PF do IBGE.e dos resultados do modelo (3).

Os períodos exatos de recessão identificados neste trabalho são apresentados na Tabela 5, incluindo as datações obtidas por Morais (2013) para dados trimestrais com base no modelo de Hamilton (1989).

Tabela 5 - Estimativa dos ciclos recessivos da indústria do Rio Grande do Sul

\begin{tabular}{c|c}
\hline Morais (2013) & Modelo heterocedástico com $p=4$ e $n=2$ \\
\hline 2001-IV a 2002-I & 2002-02 a 2002-09 \\
\hline 2002-IV a 2003-III & 2003-04 a 2003-09 \\
\hline 2004-III a 2006-II & 2005-08 a 2004-12 $2006-03$ \\
\hline 2006-IV a 2006-IV & $2007-04$ a 2007-06 \\
\hline 2007-III a 2007-III & $2008-04$ a 2008-12 \\
\hline 2008-II a 2008-II & $2010-01$ a 2010-04 \\
\hline \multirow{5}{*}{} & $2010-07$ a 2010-12 \\
\hline & $2011-08$ a 2011-09 \\
\cline { 2 - 2 } & $2011-11$ a 2012-08 \\
\cline { 2 - 2 } & $2013-11$ a 2015-10 \\
\cline { 2 - 2 } & $2016-01$ a 2016-05 \\
\cline { 2 - 2 } & $2016-12$ \\
\cline { 2 - 2 } &
\end{tabular}

Fonte: Elaboração própria a partir dos resultados do modelo (3). 
Nota-se que, no período comum a ambos os trabalhos, 2002 a 2008, há recessões com datações semelhantes. Os dois estudos encontraram um período de recessão no primeiro trimestre de 2002, mas nesse mesmo ano Morais (2013) capta um ciclo recessivo no quarto trimestre que neste trabalho não se obteve. No ano de 2003, estimou-se aqui uma recessão maior, durante praticamente todo o segundo e terceiro trimestres, enquanto o outro estudo identificou apenas no terceiro trimestre. Nos anos de 2004 a 2006, Morais (2013) estima um ciclo recessivo que durou do terceiro trimestre de 2004 até o segundo trimestre de 2006 e depois também no quarto trimestre de 2006. Entretanto, neste trabalho foram encontrados os seguintes períodos recessivos: terceiro e quarto trimestres de 2004, terceiro trimestre de 2005 até primeiro trimestre de 2006. Em 2007, os resultados se diferem, sendo que, para Morais (2013), a estimativa da recessão foi no terceiro trimestre, e neste estudo no segundo trimestre. Por fim, em 2008 ambos os trabalhos encontraram um período recessivo no segundo trimestre, no entanto, neste estudo, a recessão dura até o final do ano. Percebe-se, então, que no mesmo período em que os trabalhos datam as recessões da indústria do Rio Grande do Sul, os resultados são, de um modo geral, semelhantes.

A Tabela 5 apresenta também a datação de recessões identificadas de 2009 a 2016, período contemplado apenas neste trabalho. Os resultados indicam que não ocorreram recessões no ano de 2009, mas o ano de 2010 já se inicia com uma recessão no primeiro trimestre e, posteriormente, no terceiro e quarto trimestres. Em 2011, após um período recessivo curto, de agosto a setembro, captou-se uma recessão com começo em novembro e que durou até agosto de 2012. Outro período recessivo encontrado, o mais extenso de toda a análise, foi de novembro de 2013 a outubro de 2015. Finalmente, em 2016 houve mais duas recessões: de janeiro a maio e em dezembro.

Após a análise da datação dos ciclos para o Rio Grande do Sul, é importante buscar compreender se e como as políticas econômicas adotadas no Brasil afetaram a economia do estado. Para tanto, estima-se o modelo quatro apresentado na seção 4. Consideram-se sete especificações, variando a defasagem máxima das variáveis de macroeconômicas de zero a seis. Em todos os modelos, foi incluída uma defasagem da variável dependente, sem a qual a análise dos resíduos indicou a presença de correlação serial. ${ }^{8}$

Finalmente, todas as especificações do modelo quatro foram estimadas por MQO aliado ao estimador robusto da matriz de variância e covariância dos coeficientes de Newey-West. Os resultados são apresentados na Tabela 6.

8 Foram consideradas defasagens adicionais da variável dependente defasada, mas as defasagens adicionais não se mostraram relevantes. Ademais, feita a inclusão da primeira defasagem, reverteram-se os resultados dos testes de correlação serial, não sendo mais rejeitada a hipótese nula de ausência de correlação serial. Embora a inclusão da variável dependente defasada possa gerar preocupação sobre endogeneidade, sem esta não foi eliminado o problema de correlação serial. 
Tabela 6 - Resultado das estimações do modelo quatro, cuja variável dependente é o logaritmo natural da chance de ocorrer recessão $\left(\ln \left(C_{t}\right)\right)$

\begin{tabular}{|c|c|c|c|c|}
\hline \multirow{3}{*}{$\begin{array}{l}\text { Variável inde- } \\
\text { pendente }\end{array}$} & $\begin{array}{c}\text { Especificação } \\
\text { com } L=0\end{array}$ & $\begin{array}{c}\text { Especificação } \\
\text { com } L=2\end{array}$ & $\begin{array}{c}\text { Especificação } \\
\text { com } L=0\end{array}$ & $\begin{array}{c}\text { Especificação } \\
\text { com } L=2\end{array}$ \\
\hline & $\begin{array}{l}\text { MQO com o esti- } \\
\text { mador robusto de } \\
\text { Newey-West }\end{array}$ & $\begin{array}{l}\text { MQO com o es- } \\
\text { timador robusto } \\
\text { de Newey-West }\end{array}$ & $\begin{array}{l}\text { Bootstrap nos } \\
\text { resíduos }\end{array}$ & $\begin{array}{l}\text { Bootstrap nos } \\
\text { resíduos }\end{array}$ \\
\hline & $\begin{array}{c}\text { Coeficiente } \\
\text { (erro padrão) }\end{array}$ & $\begin{array}{c}\text { Coeficiente } \\
\text { (erro padrão) }\end{array}$ & $\begin{array}{l}\text { Coeficiente } \\
\text { (erro padrão) }\end{array}$ & $\begin{array}{c}\text { Coeficiente } \\
\text { (erro padrão) }\end{array}$ \\
\hline Constante & $\begin{array}{c}0.368 \\
(0.244)\end{array}$ & $\begin{array}{c}0.343 \\
(0.452)\end{array}$ & $\begin{array}{c}0.368 \\
(0.243)\end{array}$ & $\begin{array}{c}0.343 \\
(0.519)\end{array}$ \\
\hline $\operatorname{In}\left(C_{t-1}\right)$ & $\begin{array}{c}0.509 * * * \\
(0.143)\end{array}$ & $\begin{array}{c}0.462 * * * \\
(0.163)\end{array}$ & $\begin{array}{c}0.509 * * * \\
(0.065)\end{array}$ & $\begin{array}{c}0.462 * * * \\
(0.064)\end{array}$ \\
\hline Juros $_{\mathrm{t}-1}$ & - & $\begin{array}{l}-0.546 \\
(0.844)\end{array}$ & - & $\begin{array}{l}-0.546 \\
(0.929)\end{array}$ \\
\hline $\operatorname{Juros}_{\mathrm{t}-2}$ & - & $\begin{array}{c}0.606 \\
(0.915)\end{array}$ & - & $\begin{array}{c}0.606 \\
(0.967)\end{array}$ \\
\hline$\Delta \mathrm{DLSPE}_{\mathrm{t}-1}$ & - & $\begin{array}{c}0.749 \\
(1.487)\end{array}$ & - & $\begin{array}{c}0.749 \\
(1.813)\end{array}$ \\
\hline$\Delta \mathrm{DLSPE}_{\mathrm{t}-2}$ & - & $\begin{array}{c}-0.952 \\
(2.311)\end{array}$ & - & $\begin{array}{c}-0.952 \\
(1.840)\end{array}$ \\
\hline$\Delta \mathrm{DLSPF}_{\mathrm{t}-1}$ & - & $\begin{array}{c}-0.719^{* *} \\
(0.361)\end{array}$ & - & $\begin{array}{c}-0.719 * * * \\
(0.267)\end{array}$ \\
\hline$\Delta \mathrm{DLSPF}_{\mathrm{t}-2}$ & - & $\begin{array}{l}-0.620 * \\
(0.336)\end{array}$ & - & $\begin{array}{c}-0.620 * * \\
(0.268)\end{array}$ \\
\hline$\Delta$ Câmbio $_{\mathrm{t}-1}$ & - & $\begin{array}{c}1.547 \\
(2.166)\end{array}$ & - & $\begin{array}{c}1.547 \\
(2.692)\end{array}$ \\
\hline$\Delta$ Câmbio $_{\mathrm{t}-2}$ & - & $\begin{array}{c}3.979 \\
(6.045)\end{array}$ & - & $\begin{array}{c}3.979 \\
(2.628)\end{array}$ \\
\hline
\end{tabular}

Nota: $\ln \left(C_{t-1}\right)$ é a chance de a indústria estar em recessão, Juros é a taxa de juros Selic real, DLSPE é a dívida líquida do setor público do governo estadual, DLSPF é a dívida líquida do setor público do governo federal e Câmbio é a taxa de câmbio nominal. ***, ** " * indicam significância a 1\%, 5\% e 10\%, respectivamente.

Para cada uma das sete especificações consideradas, calcularam-se os critérios de informação de Akaike, Schwarz e Hannan-Quinn e realizou-se o teste LM de correlação serial. A especificação composta apenas pela primeira defasagem da variável dependente foi selecionada pelos critérios de informação de Schwarz e Hannan-Quinn, não havendo evidência de correlação serial ao nível de significância de 5\%. O critério de informação de Akaike sugeriu o modelo que inclui duas defasagens das variáveis macroeconômicas. Mais uma vez, não houve evidência de correlação serial. Conforme observado na Tabela 6, há considerável inércia na chance de ocorrer recessão, vista a relevância de sua primeira defasa- 
gem nas duas especificações selecionadas. No caso com duas defasagens das variáveis macroeconômicas, apenas a primeira e a segunda defasagens do gasto do governo federal foram (individualmente) relevantes, ao nível de significância de $10 \%$. Ambas apresentam sinal negativo, indicando que um aumento no gasto do governo federal tem associação negativa com a chance de ocorrer uma recessão na indústria do Rio Grande do Sul. Em outras palavras, a injeção de recursos do governo federal na economia estimula a indústria gaúcha.

Como a variável $\ln \left(C_{t-1}\right)$, usada no modelo quatro, é construída a partir da estimação do modelo três, estimaram-se os modelos selecionados usando-se o método de bootstrap nos resíduos para se obter os erros padrões dos coeficientes estimados. Os resultados de tais estimações também são apresentados na Tabela 6. Qualitativamente, os resultados não se alteram. Há evidência clara de inércia na chance de recessão, e as duas defasagens do gasto do governo federal são relevantes, a 5\% de significância. Nesse sentido, corrobora-se o resultado de que tais gastos têm uma associação positiva com o desempenho da indústria gaúcha.

\section{Considerações Finais}

Considerando-se o período de janeiro de 2002 até dezembro de 2016, realizou-se uma datação dos ciclos de negócios da indústria do Rio Grande do Sul por meio de modelos autorregressivos de mudança de regime e, feito isso, investigou-se como as recessões nesse setor estão associados às diversas variáveis macroeconômicas.

Os resultados indicam que nesse período a indústria gaúcha passou por frequentes oscilações, sendo datadas 13 recessões de duração média de 5,4 meses. Ao relacionar os ciclos da indústria gaúcha às variáveis macroeconômicas, alguns resultados se mostram robustos. A defasagem da variável dependente é relevante, havendo uma inércia na chance de recessão da indústria gaúcha. Além disso, defasagens da medida da dívida do governo federal apresentam coeficientes significativos e negativos, indicando que aumentos em tal gasto têm uma associação positiva com a recuperação da indústria gaúcha. 


\section{Referências}

ARAÚJO, V.; GENTIL, D. Avanços, recuos, acertos e erros: uma análise da resposta da política econômica brasileira à crise financeira internacional. IPEA. Rio de Janeiro: IPEA, 2011. (Texto para Discussão $n^{\circ} 1602$ )

BANCO CENTRAL DO BRASIL. [Site]. [Brasília, 2016?]. Disponível em: https://www.bcb.gov. br/. Acesso em: 10 fev. 2017.

BEVILAQUA, J. M. Evolução da ancoragem das expectativas durante o regime de metas para a inflação no Brasil. 2015. Trabalho de Conclusão de Curso (Graduação) - Pontifícia Universidade Católica do Rio de Janeiro, Rio de Janeiro 2015.

BILLIO, M.; CAPORIN, M.; CAZZAVILLAN, G. Dating eu15 monthly business cycle jointly using gdp and ipi. University Ca'Foscari of Venice, Dept. of Economics Research Paper Series, n. 19-07, 2007.

BOLDIN, M. D. A check on the robustness of hamilton's markov switching model approach to the economic analysis of the business cycle. Studies in Nonlinear Dynamics 83 Econometrics, v. 1, n. 1, 1996.

BRESSER-PEREIRA, L. C.; GOMES, C. O regime de metas de inflação no Brasil e a armadilha da taxa de juros/taxa de câmbio. Política monetária, bancos centrais e metas de inflação: teoria e experiência brasileira. Rio de Janeiro: FGV, 2009. p. 21-51.

BRY, G.; BOSCHAN, C. Cyclical analysis of time series: selected procedures and computer programs. NBER Technical Paper, 20, 1971.

CALDAS, B. B. et al. Relatório de análise da dívida pública do Rio Grande do Sul. Porto Alegre: FEE, 2015.

CARGNIN, A. P. et al. Quinze anos de transformações na economia e sociedade gaúchas contados pelas páginas do atlas socioeconômico do RS. Boletim Geográfico do Rio Grande do Sul, n. 24, p. 29-62, 2014.

CÉSPEDES, B. J.; CHAUVET, M.; LIMA, E. C. Forecasting brazilian output and its turning points in the presence of breaks: a comparison of linear and nonlinear models. Estudos Econômicos (São Paulo), v. 36, n. 1, p. 5-46, 2006.

CHAUVET, M.; HAMILTON, J. D. Dating business cycle turning points. Contributions to Economic Analysis, v. 276, p. 1- 54, 2006.

CHRISTOFFERSEN, P. Dating the turning points of nordic business cycles. EPRU Working Paper, n. 00/13, 2000.

CORREA, A. Diferenças e semelhanças entre países da América Latina: uma análise de Markov Switching para os ciclos econômicos de Brasil e Argentina. [S.l.]: Banco Central do Brasil, 2003. (Trabalho para discussão, n. 80) 
CORREA, A.; HILLBRECHT, R. Ciclos internacionais de negócios: uma análise de mudança de regime Markoviano para Brasil, Argentina e Estados Unidos. [S.l.]: Banco Central do Brasil, 2004. (Trabalho para discussão, n. 88)

DICKEY, D. A.; FULLER, W. A. Distribution of the estimators for autoregressive time series with a unit root. Journal of the American Statisticas Association, v. 74, p. 427-431, 1979.

FEIX, R. D.; LEUSIN JÚNIOR, S.; AGRANONIK; C. Painel do agronegócio no Rio Grande do Sul -2016. Porto Alegre: FEE, 2016.

FERREIRA, P. C.; FRAGELLI, R. A desagradável aritmética da dívida. Valor Econômico, 2015. Disponível em: www.fgv.br/professor/ferreira/FerreiraFragelliJulho15.pdf. Acesso em: 10 mar. 2017.

FOCHEZATTO, A.; GRANDO, M. Z. Efeitos da estiagem na economia do Rio Grande do Sul: uma abordagem multissetorial. Ensaios FEE, v. 32, n. 1, 2011.

GOMES, C.; AIDAR, O. Política monetária no Brasil: os desafios do regime de metas de inflação. Revista Economia Ensaios, v. 20, n. 1, 2005.

HAMILTON, J. D. A new approach to the economic analysis of nonstationary time series and the business cycle. Econometrica: Journal of the Econometric Society, p. 357-384, 1989.

IBGE. Pesquisa Industrial Mensal - Produção Física (PIM-PF). [S.1.]: IBGE, 2017. Disponível em: https://www.ibge.gov.br/estatisticas/economicas/industria/9294-pesquisa-industrial-mensalproducao-fisica-brasil.html?edicao=26540\&t=series-historicas. Acesso em: 10 fev. 2017.

KROLZIG, H.-M. Markov-switching vector autoregressions (modelling, statistical interference, and application to business cycle analysis). Berlin: Springer-Verlag, 1997.

KROLZIG, H.-M. Constructing turning point chronologies with Markov-switching vector autoregressive models: the Euro-zone business cycle. In: EUROSTAT (Ed.) Proceedings on modern tools for business cycle analysis. Monography in Official Statistics, 2003.

MEDEIROS, O. R. D.; SOBRAL, Y. D. A Markou switching regime model of the Brazilian business cycle. SSRN, 2007. Disponível em: https://ssrn.com/abstract=969503. Acesso em: 10 dez. 2016.

MORAIS, I. A. C. Ciclo e indicadores antecedentes na indústria do Rio Grande do Sul. Nova Economia, v. 23, n. 1, p. 133-154, 2013.

MORAIS, I. A. C.; PORTUGAL, M. S. Business cycle in the industrial production of brazilian states. In: ENCONTRO NACIONAL DE ECONOMIA, 31., 2003, Porto Seguro. Anais [...] Porto Seguro: [s.n.], 2003.

MORAIS, I. A. C.; PORTUGAL, M. S. Um novo índice coincidente para a atividade industrial do estado do Rio Grande do Sul. Estudos Econômicos (São Paulo), v. 37, n. 1, p. 35-70, 2007.

PHILLIPS, P. C. B.; PERRON, P. Testing for a unit root in time series regression. Biometrika, v.75, n. 2, p. 335-346, 1988. 
RISCO, G. R. M. Principais atividades no valor adicionado dos municípios do RS. Carta de Conjuntura FEE, 2017.

SILVA, C. G.; PIRES, M. C. C.; TERRA, F. H. B. The effects of public debt management on macroeconomic equilibrium: an analysis of the Brazilian economy. EconomiA, v. 15, n. 2, p. 174-188, 2014.

TOREZANI, T. A. O desempenho exportador do rio grande do sul em 2016. Carta de Conjuntura FEE, 2016.

VIEIRA, H. P.; PEREIRA, P. L. V. Um estudo sobre os ciclos de negócios brasileiro (19002012). São Paulo: FGV, 2014. (Textos para Discussão, 357)

Recebido em: 18/09/2017.

Aceito em: 10/05/2018.

(cc) BY 